\title{
Global infant mortality trends and attributable determinants - an ecological study using data from 192 countries for the period 1990-2011
}

Benn KD Sartorius ${ }^{1 *}$ and Kurt Sartorius ${ }^{2}$

\begin{abstract}
Background: Infant mortality rate (IMR) is regarded as an important indicator of population health. IMR rates vary substantially with the highest found in sub-Saharan Africa (SSA) compared to the lowest in Europe. Identifying spatial disparities in IMR and quantifying attributable risk factors is essential for policymakers when tailoring time-appropriate interventions at a global, regional, and country level.

Methods: Data for 192 countries were extracted from the World Bank Development Indicator database for the period 1990-2011. Spatial clustering was used to identify significant higher-risk IMR countries. A robust ecological generalized linear negative binomial regression model was used to quantify risk factors and associated decomposition values (Shapley).

Results: Significant reductions were observed in IMR for all of the World Health Organization regions for the period 1990-2011 except for SSA, which indicated a reversal of this trend in the 1990s due to HIV. Significant high-risk clustering of IMR is also indicated in SSA countries and parts of Asia. Maternal mortality (survival), lack of water and sanitation and female education were confirmed as prominent and high attributable risk factors for IMR. Distinct temporal changes in the attributability of these factors were observed, as well as significant heterogeneity with regards to the most attributable factor by region and country.

Conclusions: Our study suggests that maternal mortality is the most prominent attributable risk factor for infant mortality, followed by lack of access to sanitation, lack of access to water, and lower female education. Variation exists across regions and countries with regards to the most attributable factor. Our study also suggests significant underestimation of IMR in regions known for poorer data quality. The results will aid policymakers in re-tailoring time-appropriate interventions to more effectively reduce IMR in line with Millennium Development Goal 4.
\end{abstract}

Keywords: Infant mortality, Global, Spatial risk, Trends, Determinants, Population attributable fractions

\section{Background}

Infant mortality rate (IMR) is generally regarded as an important national indicator of health because it is particularly sensitive to general structural factors, like socioeconomic development and basic living conditions [1]. There has been a steady decline in global and regional

* Correspondence: Sartorius@ukzn.ac.za

'Discipline of Public Health Medicine, School of Nursing and Public Health,

George Campbell Building, Howard College Campus, University of

KwaZulu-Natal, Durban 4001, South Africa

Full list of author information is available at the end of the article
IMR over the last century, with the exception of subSaharan Africa (SSA) which experienced a reversal in this trend from the late 1990s due to the HIV pandemic [2,3]. Reducing infant mortality in line with Millennium Development Goal (MDG) 4 remains a key challenge [2], especially given the large inter-regional variation of this indicator. The highest IMR can be found in SSA (75 infant deaths per 1000 live births), while lower rates are found in developed countries like Europe (11 infant deaths per 1000

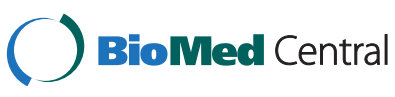

(c) 2014 Sartorius and Sartorius; licensee BioMed Central Ltd. This is an Open Access article distributed under the terms of the Creative Commons Attribution License (http://creativecommons.org/licenses/by/4.0), which permits unrestricted use,

distribution, and reproduction in any medium, provided the original work is properly credited. The Creative Commons Public Domain Dedication waiver (http://creativecommons.org/publicdomain/zero/1.0/) applies to the data made available in this article, unless otherwise stated. 
live births) [4]. Inter-country variation is even greater between these two regions, where there is a 57-fold difference between Sierra Leone (SSA) with an IMR of 114, compared to Sweden with an IMR of 2 [4]. The differential levels of IMR underline the need to identify and target spatial hotspots of high mortality if MDG 4 goals are to be attained at a regional and global level.

Understanding the relative importance of IMR risk factors and how they vary by country and region is an essential tool for policymakers. Infant mortality can be attributed to a range of hierarchical determinants that include proximal (e.g., infectious), intermediate (e.g., water and sanitation), and distal (e.g., socio-economic status, education) factors [5]. Poor sanitation and unsafe drinking water, for example, are important intermediate determinants of IMR as a result of diarrhea [6]. More distal determinants, like low economic status and poor education, however, mediate less access to health care, as well as promote higher risk behavior [7].

Attributable fractions $\left(\mathrm{AF}_{p}\right)$ are helpful tools for public health planning [8] and are often underutilized. Risk factor effects (e.g., relative risks or odds ratios) are insufficient in isolation as they do not take into account the fraction of a given population that is exposed to a given risk factor. $\mathrm{AF}_{p}$, often applied to mortality, estimate the proportion of deaths that can be ascribed to a particular risk exposure [8]. It is particularly important to establish the total effect (or population impact) of an attributable risk factor for IMR in order to prioritize interventions [9] that can effectively guide policymakers to target the largest risk factors in a given country or region. Furthermore, the validity of the AFp approach using adjusted regression coefficients in quantifying the relative importance of different factors against more commonly used decomposition approaches such as Shapley [10] is also of importance. The magnitude of the contribution from each factor may not be accurately estimated by the regression (e.g., residual confounding) leading to potentially over- or underestimated AFp estimates [11]. This is particularly relevant to ecological data, which cannot be disaggregated to show discrete exposure to each determinant. Also, variables not classified as a prevalence of exposure (i.e., proportion) are problematic, as the AFp cannot be directly calculated using traditional formulae [11].

This study aimed to identify spatial hotspots for infant mortality in 2011, as well as quantify the attributability ("impact") of hierarchical determinants of infant mortality based on country-level prevalence's of exposure. The study also establishes temporal trends in attributability by factor and region as well as country for the period 1990-2011 and maps the most important or attributable factors in 2011 as a guide for policymakers to tailor interventions at a country level based on the latest estimates. In particular, the paper makes a contribution by using global country-level data to identify important factors, both regionally and nationally, to help sharpen policy guidance, as well as to monitor progress towards the relevant MDGs.

\section{Methods}

\section{Data sources}

Selected distal, intermediate, and proximate determinants for IMR that were based on existing literature $[2,5,12]$ are illustrated in the adapted conceptual framework below (Figure 1). Country-level IMR and available hierarchical determinants, such as HIV prevalence, access to water and sanitation, female education, maternal

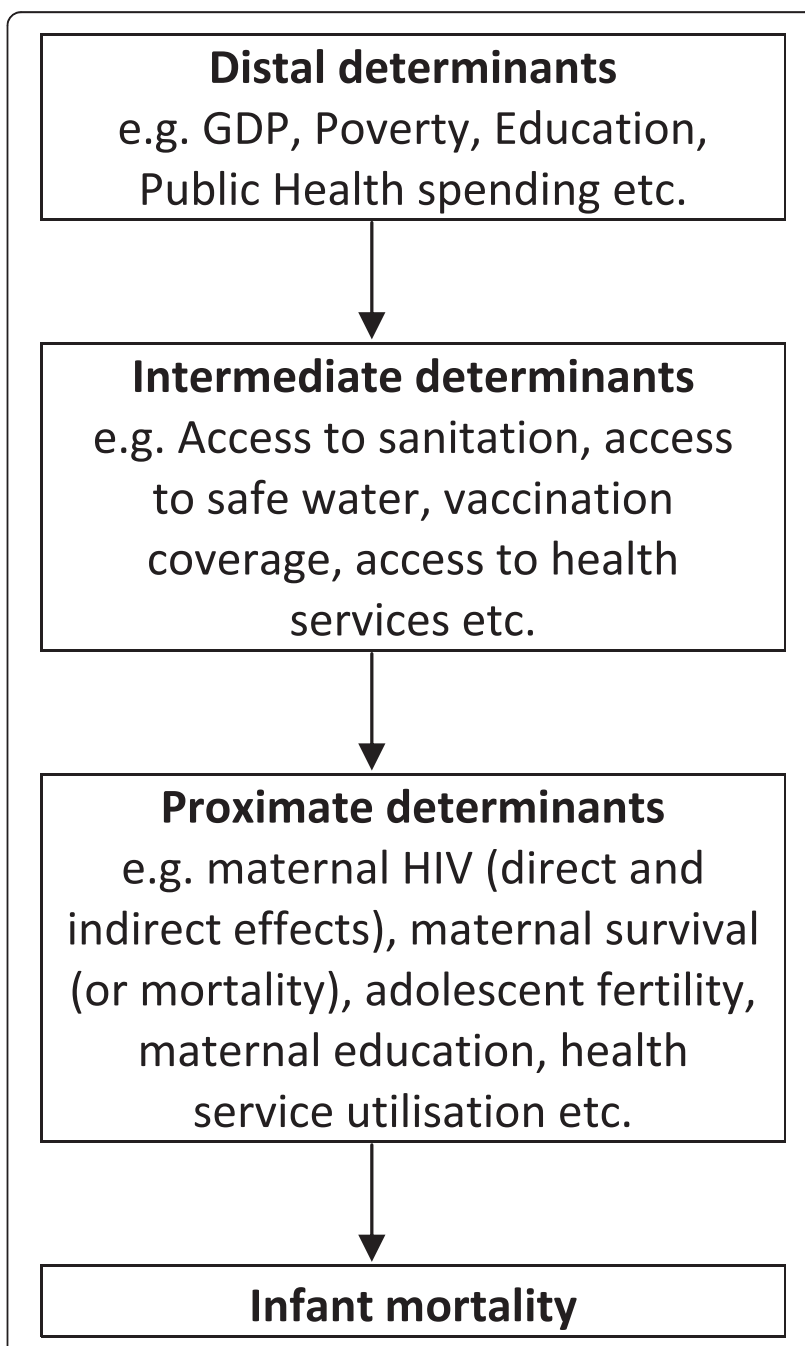

Figure 1 Conceptual framework of the hierarchy of determinants for infant mortality. Adapted from $[2,5]$. 


\begin{tabular}{|c|c|c|c|c|}
\hline Indicator & $\begin{array}{l}\text { Number of non-missing } \\
\text { data points }(N=4224) n(\%)\end{array}$ & Original source & $\begin{array}{l}\text { Approach used to estimate } \\
\text { missing values within } \\
\text { country in our study }\end{array}$ & $\begin{array}{l}\text { Number of non-missing } \\
\text { data points following } \\
\text { re-estimation }(\mathrm{N}=4224) \mathrm{n}(\%)\end{array}$ \\
\hline $\begin{array}{l}\text { IMR (per } 1000 \text { live births) - } \\
\text { no denominator }\end{array}$ & $4224(100 \%)$ & $\begin{array}{l}\text { Estimates developed by the UN Inter-agency Group for } \\
\text { Child Mortality Estimation (UNICEF, WHO, World Bank, } \\
\text { UN DESA Population Division). }\end{array}$ & - & - \\
\hline $\begin{array}{l}\text { Live births (calculated } \\
\text { from crude birth rate } \\
\text { versus total population } \\
\text { estimates) - offset for } \\
\text { regression model }\end{array}$ & $4098(97.9 \%)$ & $\begin{array}{l}\text { (1) United Nations Population Division. World Population } \\
\text { Prospects, } \\
\text { (2) United Nations Statistical Division. Population } \\
\text { and Vital Statistics Report (various years), } \\
\text { (3) Census reports and other statistical publications } \\
\text { from national statistical offices, } \\
\text { (4) Eurostat: Demographic Statistics, } \\
\text { (5) Secretariat of the Pacific Community: Statistics } \\
\text { and Demography Programme, and } \\
\text { (6) U.S. Census Bureau: International Database. }\end{array}$ & Linear, within country & $4224(100 \%)$ \\
\hline Number of infant deaths & $4224(100 \%)$ & Calculated from the two indicators above. & - & - \\
\hline $\begin{array}{l}\text { No access to water } \\
\text { (100- percentage of } \\
\text { population with access } \\
\text { to improved water) }\end{array}$ & $4102(97.1 \%)$ & $\begin{array}{l}\text { WHO/UNICEF Joint Monitoring Programme } \\
\text { (JMP) for Water Supply and Sanitation. }\end{array}$ & Linear, within country & $4180(99.0 \%)$ \\
\hline $\begin{array}{l}\text { Children ( }<12 \text { months) } \\
\text { not immunized against } \\
\text { DPT }\end{array}$ & $4079(96.6 \%)$ & WHO and UNICEF. & Linear, within country & $4200(99.4 \%)$ \\
\hline GDP per capita (in US\$) & $4032(95.5 \%)$ & $\begin{array}{l}\text { World Bank national accounts data, and } \\
\text { OECD National Accounts data files. }\end{array}$ & $\begin{array}{l}\text { Non-linear (second order } \\
\text { polynomial), within country }\end{array}$ & $4169(98.7 \%)$ \\
\hline $\begin{array}{l}\text { No access to sanitation } \\
\text { (100- percentage of } \\
\text { population with access to } \\
\text { improved sanitation facilities) }\end{array}$ & $3930(93.0 \%)$ & $\begin{array}{l}\text { WHO/UNICEF Joint Monitoring Programme } \\
\text { (JMP) for Water Supply and Sanitation. }\end{array}$ & Linear, within country & $4136(97.9 \%)$ \\
\hline \multirow[t]{2}{*}{$\begin{array}{l}\text { HIV prevalence } \\
\text { (15-49 years) }\end{array}$} & \multirow[t]{2}{*}{$3212(76.0 \%)$} & \multirow[t]{2}{*}{ UNAIDS estimates. } & $\begin{array}{l}\text { (1) Non-linear (second order } \\
\text { polynomial), within country. }\end{array}$ & $4212(99.7 \%)$ \\
\hline & & & $\begin{array}{l}\text { (2) Countries with no } \\
\text { observations, based } \\
\text { on neighboring WHO } \\
\text { subregion values. }\end{array}$ & \\
\hline $\begin{array}{l}\text { Out-of-pocket health } \\
\text { expenditure }(\% \text { of private } \\
\text { expenditure on health) }\end{array}$ & $3181(75.3 \%)$ & $\begin{array}{l}\text { World Health Organization National Health } \\
\text { Account database. }\end{array}$ & Linear, within country & $4148(98.2 \%)$ \\
\hline $\begin{array}{l}\text { Adolescent fertility rate } \\
\text { (number of births per } 1,000\end{array}$ & $2700(63.9 \%)$ & $\begin{array}{l}\text { United Nations Population Division, World } \\
\text { Population Prospects. }\end{array}$ & Linear, within country & $3982(94.3 \%)$ \\
\hline
\end{tabular}


Table 1 Data used in this study and approach used to impute missing covariate data, 1990-2011 (Continued)

\begin{tabular}{|c|c|c|c|c|}
\hline \multirow[t]{2}{*}{$\begin{array}{l}\text { Maternal mortality ratio } \\
\text { (per 100,000 live births) }\end{array}$} & \multirow[t]{2}{*}{$\begin{array}{l}910(21.5 \%) \text {, data points only } \\
\text { for } 1990,1995,2000,2005 \\
2010\end{array}$} & $\begin{array}{l}\text { Hogan et al. Maternal mortality for } 181 \text { countries, } \\
\text { 1980-2008: a systematic analysis of progress } \\
\text { towards Millennium Development Goal } 5 . \\
\text { Lancet. } 2010 \text { May 8; 375(9726):1609-23. } \\
\text { doi:10.1016/S0140-6736(10)60518-1. }\end{array}$ & \multirow[t]{2}{*}{ Linear, within country } & \multirow[t]{2}{*}{$4002(94.7 \%)$} \\
\hline & & $\begin{array}{l}\text { UNICEF, State of the World's Children, Childinfo, and } \\
\text { Demographic and Health Surveys by ICF International. }\end{array}$ & & \\
\hline \multirow{2}{*}{$\begin{array}{l}\text { Female education (mean } \\
\text { number of years of education } \\
\text { for female adults aged } \\
25+\text { years) }\end{array}$} & \multirow{2}{*}{$\begin{array}{l}348(8.2 \%) \text {, data points only } \\
\text { for } 1970,1990,2009\end{array}$} & \multirow{2}{*}{$\begin{array}{l}\text { Gakidou et al. Increased educational attainment and its } \\
\text { effect on child mortality in } 175 \text { countries between } 1970 \\
\text { and 2009: a systematic analysis. The Lancet - } 18 \text { September } \\
2010 \text { (Vol. 376, Issue 9745, Pages 959-974) doi:10.1016/ } \\
\text { S0140-6736(10)61257-3. }\end{array}$} & (1) Linear, within country & \multirow{2}{*}{$4068(96.3 \%)$} \\
\hline & & & $\begin{array}{l}\text { (2) Regress against"Progression } \\
\text { to secondary school amongst females". }\end{array}$ & \\
\hline $\begin{array}{l}\text { Progression to secondary } \\
\text { school amongst females (\%) }\end{array}$ & $1541(36.5 \%)$ & UNESCO Institute for Statistics. & Linear, within country & $3427(81.1 \%)$ \\
\hline $\begin{array}{l}\text { Primary education } \\
\text { non-completion amongst } \\
\text { females (\%) }\end{array}$ & $2163(51.2 \%)$ & UNESCO Institute for Statistics. & Linear, within country & $2985(70.7 \%)$ \\
\hline
\end{tabular}


survival, gross domestic product (GDP) per capita based on midyear population (poverty proxy), out-of-pocket health expenditure (\% of total expenditure on health), and vaccination coverage were extracted from the World Development Indicators (WDI) database for the period 1990-2011 [13]. A detailed list of the original source(s) for each of the indicators is provided in Table 1 below. Our dataset was restricted to the 192 countries that had complete IMR data for the period 1990-2011. This included 192 countries $\times 22$ years (4224 observations per variable). The overall completeness of the selected indicators is indicated in Table 1 . The most complete predictor was lack of access to water $(97.1 \%$ or 4102 observations) followed by Diphtheria-Pertussis-Tetanus (DPT) immunization at 24 months (96.6\%), GDP (US\$) per capita (95.5\%), and lack of sanitation (93.0\%).

Data for female education were additionally sourced from Gakidou et al. [14] which compiled data for mean number of years of education for adults (25+) further stratified by gender for 175 countries for the years 1970, 1990, and 2009. We also sourced data for maternal mortality ratios from [15], which compiled data for 181 countries for the years 1990, 1995, 2000, 2005, and 2010.

Other potentially important determinants (e.g., maternal mortality ratio, female education) contained a large proportion of missing values.

We attempted to improve the completeness of the covariate data listed in Table 1 (e.g., HIV prevalence etc.) by replacing missing observations within a given country with values predicted by a linear and/or non-linear temporal trend approach. For all covariates observed versus fitted values at observed data time points were compared to check whether a linear trend or non-linear (higher-order polynomial) was more appropriate.

\section{Data analysis}

We employed an ecological country-level generalized linear negative binomial modeling approach to estimate risk ratios (RR) for each determinant versus the IMR outcome. This was used instead of a Poisson approach as there was evidence of significant overdispersion in the data. The outcome variable was the count of infant deaths in a given country and year. We used number of live births in a given country and year as the offset in the model (Table 1). Factors significant at the 10\% level $(\mathrm{p}<0.1)$ in the bivariate regression were selected for inclusion into the final multivariable model. We used robust error variance in our model [16] and clustered on the unit of analysis (country) to correctly adjust the standard errors and not overestimate significance of the determinants. Multicollinearity was assessed using variance inflation factors (VIF), given that many of the predictors are likely to be highly correlated to one another.
As a general rule of thumb a variable whose VIF values are greater than 10 may affect the regression results [17]. We checked the individual and overall VIF of covariates included in the final multivariable model for the presence of potential multicollinearity.

We also assessed the degree to which country-level prevalence of exposure to a given variable (e.g., access to water and sanitation) impacted IMR. Population attributable fractions $(\mathrm{AF} p)$ are commonly calculated in terms of the prevalence of exposure $\left(P_{e}\right)$ to a given risk factor in the population and the relative risk (RR) of the outcome for those exposed to that risk factor:

$$
A F p=\frac{P_{e}(R R-1)}{1+P_{e}(R R-1)}
$$

Given that $\mathrm{AF} p$ are susceptible to confounding (i.e., incorrect estimation of the RR when unadjusted) [11], multivariable adjusted coefficients are preferred for use in the final $\mathrm{AF} p$ calculation and were used in this study. The 95\% confidence limits for the coefficient was also useful for quantifying the range of $\mathrm{AF} p$ associated with a given determinant and were estimated. Furthermore, we estimated the relative contribution (importance) of each covariate based on the Shapley regression-based decomposition approach for distributional analysis [10]. This was compared to relevant AFps. Shapley estimates are presented in our results for reasons discussed earlier (see introduction) and also because the AFps did not correlate well with the calculated Shapley decomposition values e.g. contribution of out of pocket health expenditure appeared overestimated based the conventional $\mathrm{AF} p$ approach.

A local Moran's I statistic with Empirical Bayes (EB) rate adjustment (in this case infant deaths scaled by total live births) was used to identify the existence of significant spatial clustering of infant mortality incorporating threshold neighboring country contiguity. This EB approach was preferred as it better accounts for differences in underlying population density or heterogeneity (in this case differing denominators of live births in each country) [18]. Furthermore this approach allows more detailed classification of spatial clustering into four groups (high-high, high-low, low-high, and low-low) instead of two (high or low). GeoDa [19] implements the recommended EB standardization procedure in its global Moran scatter plot and LISA maps (i.e., standardization of the raw rates). However, for the identification of significant clustering (similarity) of high AFp, we used the Getis and Ord local G statistic (or Gi* statistic) $[20,21]$, as the heterogeneous denominator issue does not apply (i.e., all scaled out of $100 \%$ ). Significance was set at $5 \%$ after 99,999 iterations. 


\section{Software}

The regression analysis was run in Stata 12.0 SE [22]. The spatial clustering analysis and mapping was performed using GeoDa [19].

\section{Results}

Global and income category trends in IMR (1960-2011)

IMR declined steadily in all regions for the period 1960-2011, except for SSA where IMR reductions almost ceased during the late 1980s through to the 1990s (Figure 2a). The gap between middle- and high-income countries (MIC-HIC) and low income countries (LIC) held constant until the 2000s, after which the gap between these two groups diminished (Figure 2a). LIC IMR increased relative to HIC and
MIC until the late 1990s, after which it has stabilized at a constant level ( 10 - and 1.6-fold higher, respectively) (Figure $2 \mathrm{~b}$ ). This ratio increased markedly during the late 1990s when comparing LIC to HIC whereas the gap (ratio) between LIC and MIC appeared to decrease during this period.

\section{Spatial distribution and clustering of IMR in 2011}

IMR was markedly higher in Africa (especially SSA) and parts of central and Southeast Asia in 2011 (Figure 3a). Significant spatial clustering of highsurrounded by high IMR was largely confined to sub-Saharan Africa (most of the region emerged as a high-risk cluster) with some countries in Central Asia, the Middle East, and Cuba (Figure 3b) (i.e.,
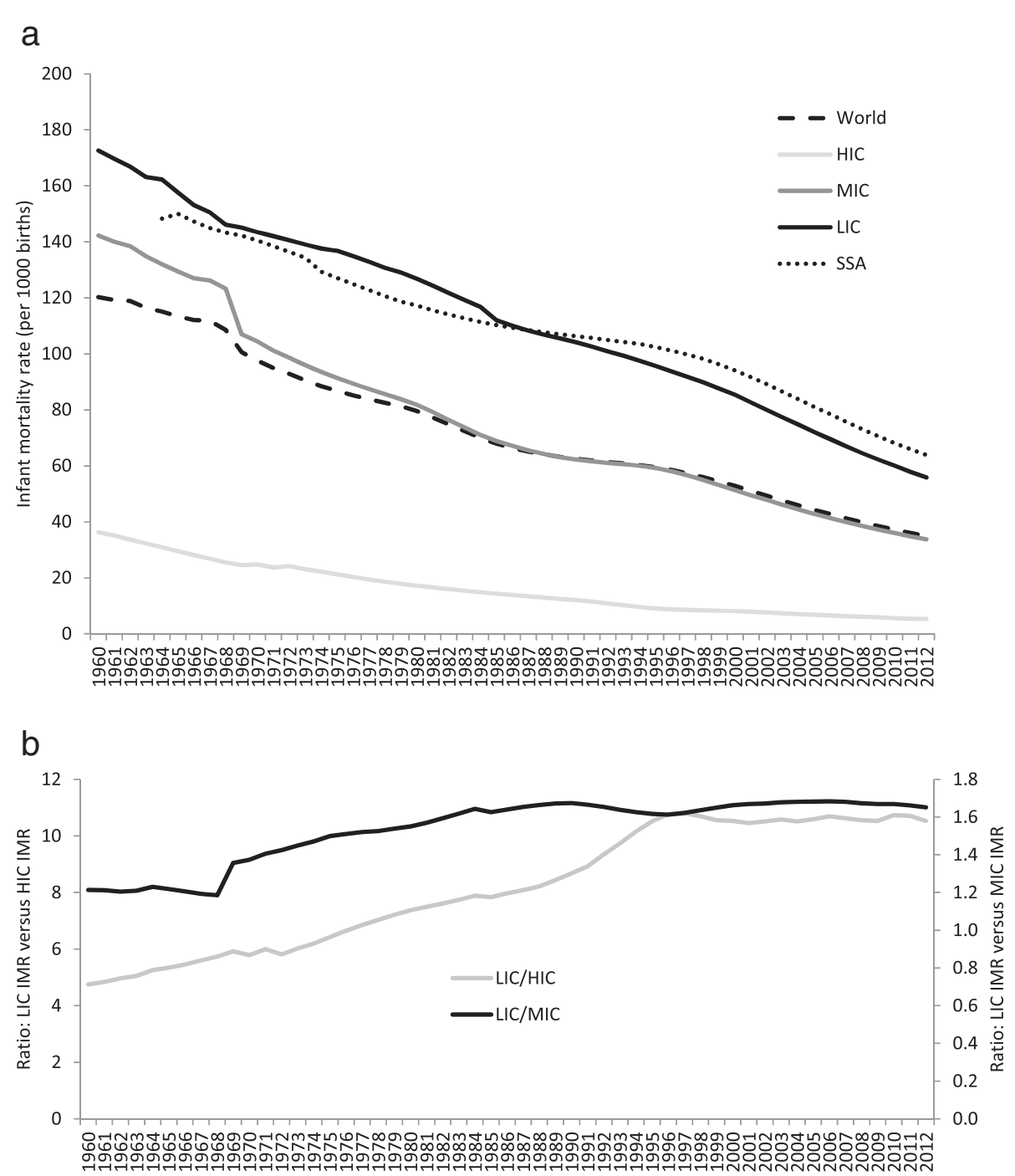

Figure 2 Infant mortality trends by region (a) and ratio of IMR of low-income countries (LIC) versus middle-income countries (MIC) and high-income countries (HIC) (b) during 1960-2011. 


\section{a}
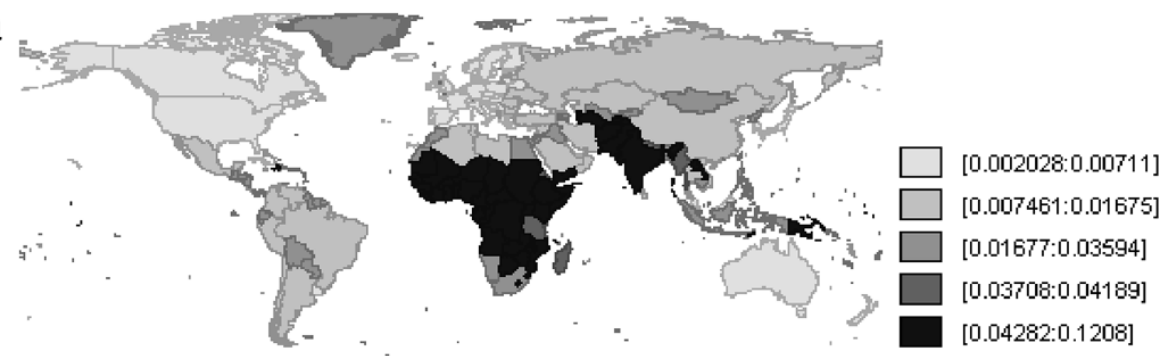

b

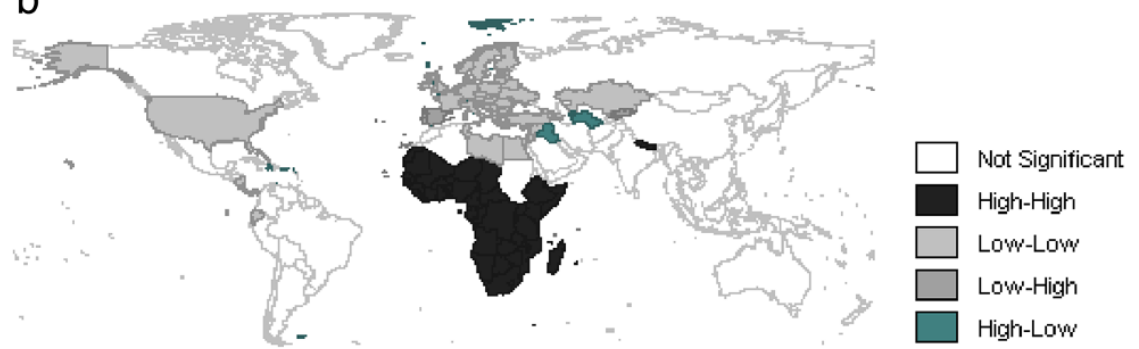

Figure 3 IMR rate (equal intervals, Empirical Bayes adjustment) (a) and significant spatial clustering of IMR based on local Moran's I with Empirical Bayes adjustment (b) in 2011.

one large focal hotspot area with other disseminated hot spots). Significant low-surrounded by low clustering was largely confined to Europe and was also observed in the United States.

\section{Determinants of IMR and relative importance (Shapley decomposition value) of each}

A summary of the determinants included in our analysis is presented in Table 2 .

Following multivariable adjustment, increasing HIV prevalence among adults aged 15 to 49 years was associated with the highest adjusted relative risk (IRR $=1.033, \mathrm{p}<0.001)$, followed by out-of-pocket health expenditure (IRR $=1.006, \mathrm{p}<0.001)$ and increasing lack of access to sanitation (IRR $=1.004$, $\mathrm{p}=0.026$ ) (see Table 3). Increasing lack of access to water and increasing proportion of children not immunized against DPT were marginally significant following multivariable adjustment. Increasing GDP per capita (in US\$) and mean number of education years amongst females aged 25+ were associated with a significant lowering of IMR.

Table 2 Summary of selected determinants for IMR using data from 192 countries, 1990-2011 [note: please refer to Table 1 for further details regarding number of observations]

\begin{tabular}{lll}
\hline Indicator & Median (IQR') & Range (minimum-maximum) \\
\hline IMR (per 1,000 live births) & $25.4(11-60.5)$ & $1.8-165.5$ \\
No access to water (\%) & $11.9(2.3-28.4)$ & $0.0-100.0$ \\
Children (<12 months) not immunized against DPT (\%) & $10.0(4.0-25.0)$ & $1.0-92.0$ \\
GDP per capita (in US\$) & $2257.5(676.6-8335.0)$ & $19.3-193892.3$ \\
No access to sanitation (\%) & $20.4(3.5-60.8)$ & $0.0-97.7$ \\
HIV prevalence (15-49 years) (\%) & $0.5(0.1-2.0)$ & $0.0-27.4$ \\
Out-of-pocket health expenditure (\%) & $32.1(17.8-50.2)$ & $0.0-99.6$ \\
Adolescent fertility rate (births per 1,000 women aged 15-19) & $48.3(21.6-90.8)$ & $0.5-282.8$ \\
Maternal mortality ratio (per 100,000 live births) & $82.3(22.0-408.1)$ & $0.2-2540.0$ \\
Female education (mean number of years of education) & $6.5(3.1-9.5)$ & $0.2-14.7$ \\
\hline
\end{tabular}


Table 3 Selected modifiable determinants for IMR areas based on a bivariate and multivariable robust negative binomial ecological regression and including population attributable fractions (AFp) as well as Shapley decomposition values, 1990-2011

\begin{tabular}{llllll}
\hline Determinant & $\begin{array}{l}\text { Unadjusted RR } \\
(\mathbf{9 5 \%} \mathbf{C l})\end{array}$ & $\begin{array}{l}\text { Unadjusted } \\
\mathbf{p} \text {-value }\end{array}$ & $\begin{array}{l}\text { Adjusted RR } \\
\mathbf{( 9 5 \% ~ C l )}\end{array}$ & $\begin{array}{l}\text { Adjusted } \\
\text { p-value }\end{array}$ & Shapley decomposition value \\
\hline No access to water & $1.042(1.036-1.049)$ & $<0.001$ & $1.007(0.999-1.015)$ & 0.079 & 0.106 \\
Infants not immunized against DPT & $1.032(1.028-1.036)$ & $<0.001$ & $1.003(1.000-1.007)$ & 0.089 & 0.107 \\
GDP per capita & $0.999(0.999-0.999)$ & $<0.001$ & $0.999(0.999-0.999)$ & $<0.001$ & 0.038 \\
No access to sanitation & $1.025(1.021-1.028)$ & $<0.001$ & $1.004(1.000-1.008)$ & 0.026 & 0.131 \\
HIV prevalence (15-49 years) & $1.077(1.039-1.117)$ & $<0.001$ & $1.033(1.022-1.044)$ & $<0.001$ & 0.024 \\
Out-of-pocket health expenditure & $1.019(1.014-1.025)$ & $<0.001$ & $1.006(1.003-1.009)$ & $<0.001$ & 0.038 \\
Adolescent fertility rate & $1.013(1.011-1.015)$ & $<0.001$ & $1.001(0.999-1.002)$ & 0.231 & 0.109 \\
Maternal mortality ratio & $1.002(1.002-1.002)$ & $<0.001$ & $1.000(1.000-1.001)$ & 0.001 & 0.224 \\
Female education years & $0.816(0.797-0.836)$ & $<0.001$ & $0.947(0.923-0.971)$ & $<0.001$ & 0.110 \\
Constant (mean baseline IMR per 1000) & - & - & $21.9(17.1-28.1)$ & $<0.001$ & -
\end{tabular}

Based on prevalence of exposure and risk coefficient, the most attributable (or important) factor overall was maternal mortality (Table 3). The Shapley decomposition value for this factor was $22.4 \%$. This is followed by a lack of access to sanitation (13.1\%), female education (11.0\%), adolescent fertility (10.9\%), lack of immunization (10.7\%), and lack of access to water (10.6\%). HIV, GDP per capita, and out-of-pocket health expense appeared to be the "least" important based on the Shapley decomposition values for the examined determinants.

Furthermore, as illustrated in Figure 4, maternal mortality and lack of access to sanitation or water were the most important factor in 100 countries globally. Lack of sanitation appeared to the most prominent factor in Central-South America while a more heterogeneous mixture of the three factors described above were observed in SSA and Eastern Europe-Asia. HIV prevalence appeared to be the least important factor at a global level based on the determinant Shapley decomposition values (Table 3). However, at a country level, HIV in Southern Africa remains the most high-impact and spatially concentrated determinant of IMR (see Appendix 1 for additional analyses). Variation and significant spatial concentration of Shapley decomposition values for other selected determinants included in the model and by individual countries can be found in Appendix 1 .

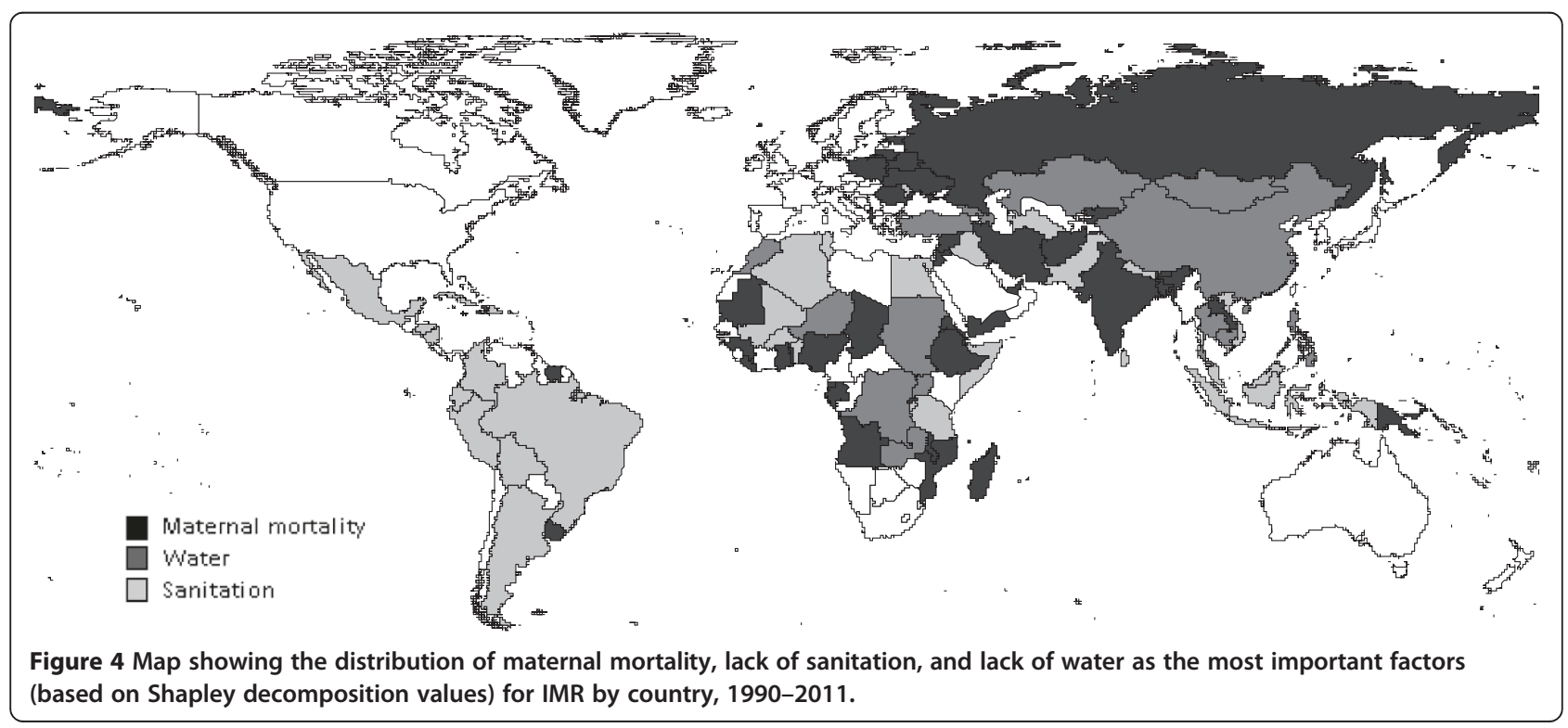


Temporal trends in relative importance of determinants globally and by continent

Figure 5 displays the temporal trends in the relative importance (decomposition values) of the determinants of IMR both globally and by continent. Globally and more specifically in Africa, the Americas, and
Asia, maternal mortality appeared to be the most important determinant (accounted for more $\mathrm{R}^{2}$ ), and this increased over the study period. Lack of sanitation featured prominently and appeared to be the secondmost important determinant globally and specifically in the Americas and Asia. In Africa lack of water

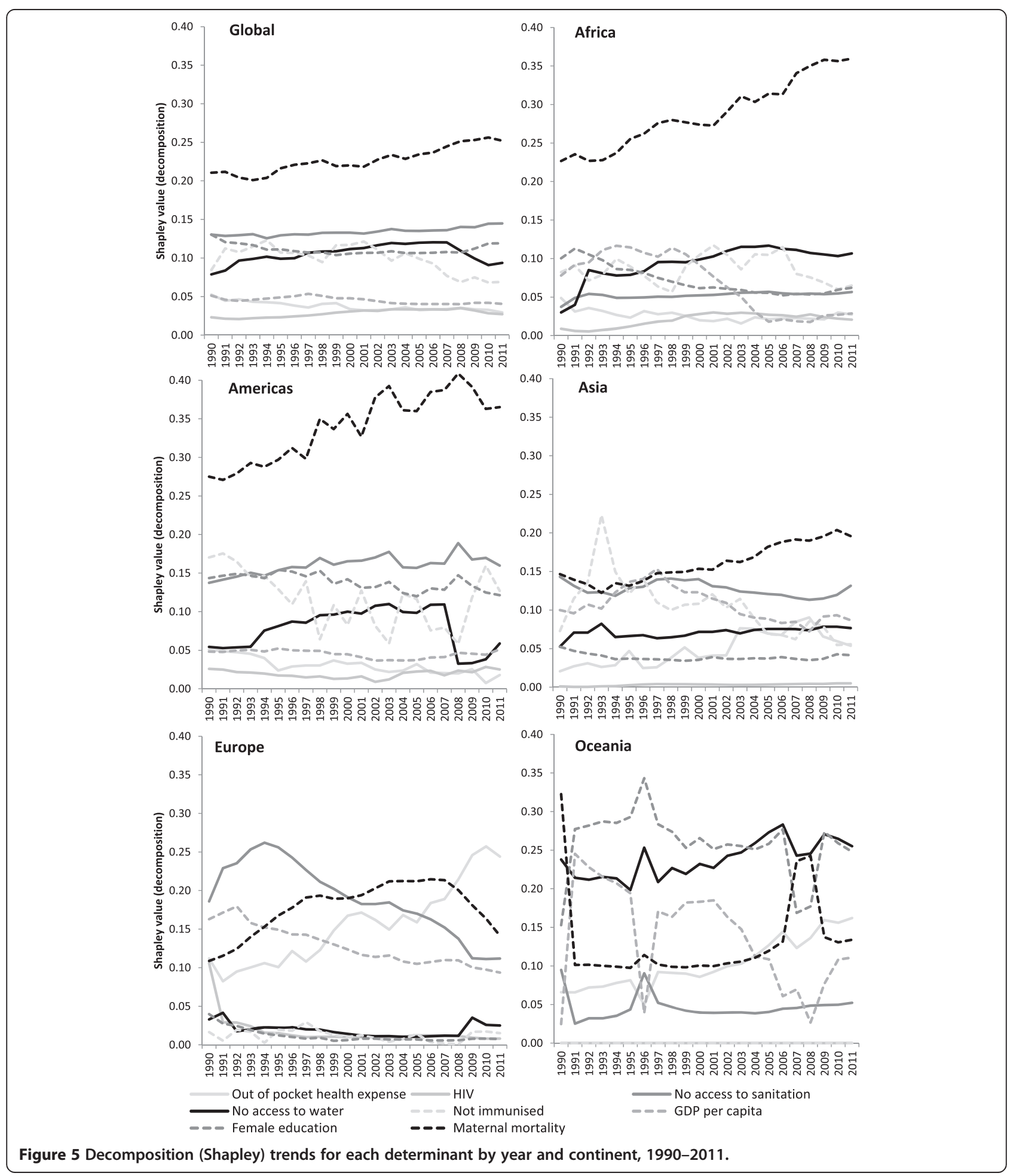


appeared to be the secondary determinant. In Europe, out-of-pocket health expenditure appeared to replace maternal mortality as the most important determinant toward the end of the study period, in contrast to the global trend.

In terms of temporal trends in relative importance at a global level, out-of-pocket health expenditure, lack of immunization, and adolescent fertility appeared to significantly decrease in relative importance over the study period. Conversely, maternal mortality and lack of access to sanitation and water appeared to increase in relative importance at the global level. HIV appeared to increase in relative importance in the late 1990 s and early 2000 s but appeared to start declining from 2009.

\section{Potential underestimation of IMR in 2011}

The predicted IMR (and standard error of the prediction) from the multivariable model (Table 3) suggests that IMR may have been significantly underreported (or underestimated) in a number of countries (Figure 6 - ordered by modeled descending IMR level), many of which were in Africa, which have known data limitations. The largest potential underestimation based on the largest absolute difference (predicted-observed IMR) was predicted in Chad $(+62)$, followed by Tanzania $(+26)$, Guinea $(+23)$, Yemen $(+20)$, and Mozambique (+19).

\section{Discussion}

Usefulness of the proposed approach for global policymakers

Little attention has been given to using secondary data to identify spatial differences and clustering in IMR and related determinants, or to the estimation of modifiable determinants and their changes. This lack of attention is especially surprising given the prominence of IMR as a policy issue in the MDG 4 objectives. A study by Black et al. [23] suggested that a "better understanding of child health epidemiology could contribute to more effective approaches to saving children's lives". The approach utilized in our study can more effectively help guide resources at a global and country level. The proposed framework is also easily adaptable to mortality in other age groups and for other health outcomes, as illustrated in other studies [24]. The framework, however, would require validation and comparison with existing frameworks, such as the Lives Saved Tool (LiST) [25], to confirm its potential routine utility.

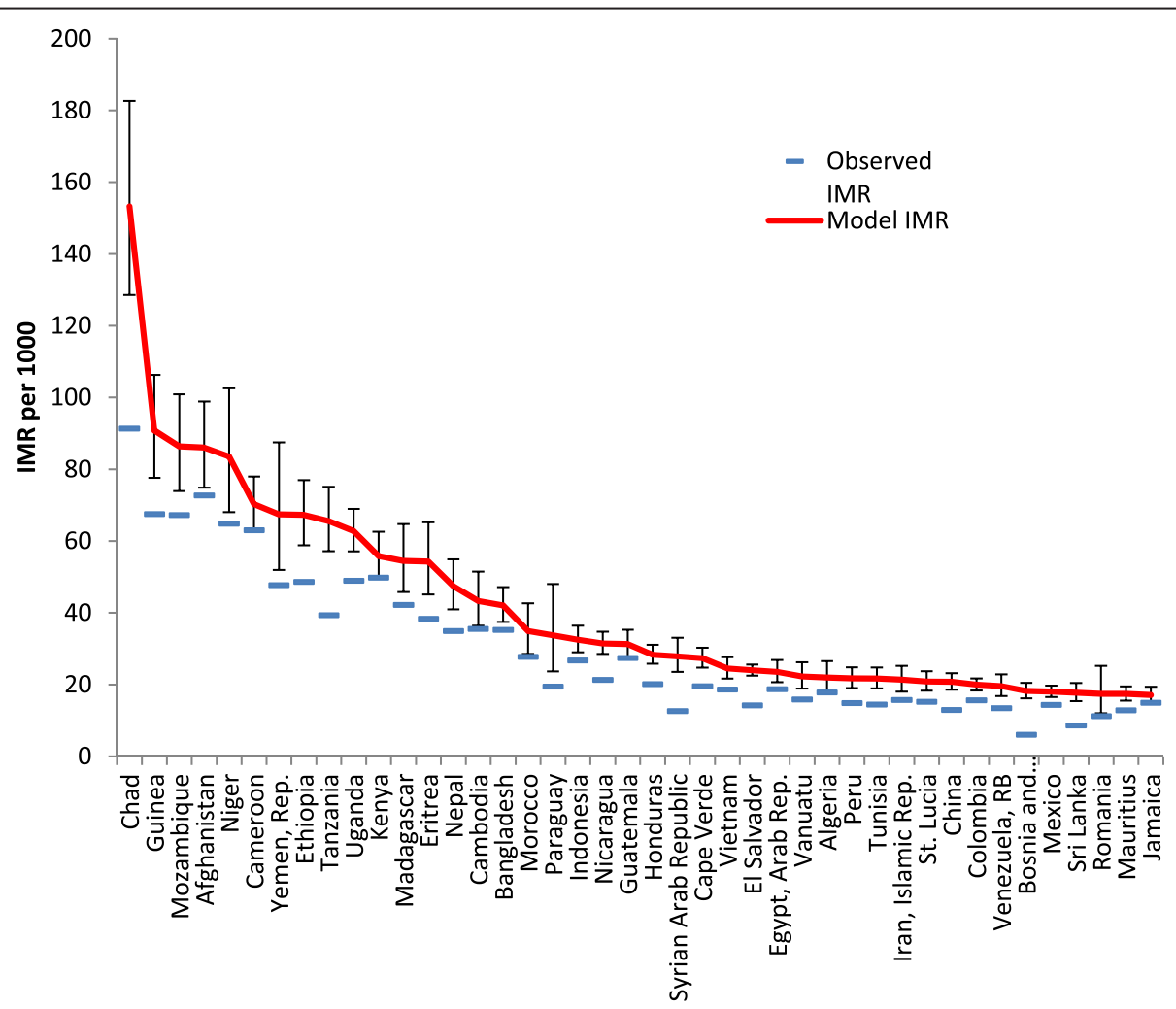

Figure 6 Significant underestimation of IMR predicted by the model based on observed determinant profiles within countries, 2011 [note: ordered by descending modeled IMR level]. 


\section{Global secondary data exploitation}

Secondary data can be used to help inform the policymaking process with respect to the global incidence of IMR and its associated determinants $[2,12]$. This study improves on previous work by including spatial inference to identify significant clustering of IMR and associated determinants that can be used to inform regional policy initiatives. It also uses attributable fractions to identify and estimate high-impact determinants that can be targeted at the country level and includes a temporal change component to assist guide time-appropriate policy decisions.

\section{Burden and spatial distribution of IMR}

The highest burden of infant mortality is observed in SSA, and this is in line with previous studies [23]. A high burden of infant mortality is also observed in central-South Asia. Previous studies have demonstrated that the burden of child mortality is highly concentred in these regions, as well as illustrating the relative gap between low- and middle-to-high-income countries [23]. Causes of infant death differ substantially from country to country, further highlighting the need to expand our understanding of infant health epidemiology at a country level rather than in larger geopolitical regions.

There is, however, substantial variation in death rates within these and other regions, further suggesting that the planning of health interventions should take place at a country level [23]. Black et al., [23], however, suggest that interventions for (more) homogeneous groups of countries are a feasible option when incomplete and/ or unreliable data are available (as is the case for many countries).

\section{Important modifiable determinants of IMR}

Increasing political attention to address inequalities in IMR needs to be accompanied by more scientific-based evidence on the contribution of specific determinants and ways to ensure that interventions reach vulnerable groups [26]. Little is known about the relative contribution of the different hierarchical determinants of IMR and its inequality, nor with regards to the impact of country- and global-level determinants. Development of interventions or priority areas for infant mortality requires an understanding of the associated determinants [23] and how the prevalence of these determinants varies from country to country. Population attributable fractions and/or decomposition values such as Shapley [10] are useful to help guide policymakers in planning public health interventions when selecting "high-impact" risk factors, [27] as demonstrated in this study.
Maternal mortality (survival) emerged as a significant and the most prominent (based on decomposition value) determinant of infant mortality based on our analyses. This has been demonstrated extensively in previous literature, for example [28-30], and is both a result of direct (e.g., vertical HIV transmission) and indirect (e.g., loss of primary caregiver, negative impact on household income) effects. Furthermore the relative importance of this determinant appeared to increase over the study period. Policymakers should take action to address this seemingly key determinant in focal countries if further progress toward reducing infant mortality in line with MDG 4 is to be made. Spatial inference suggests that SSA may be important to target first in reducing maternal mortality as a key determinant of infant mortality in the region and globally.

Unhygienic environments place infants and children at greater risk of mortality. Drinking unclean water, using unclean water for hygiene, and a lack of proper sanitation are known risk factors for infant and child mortality $[6,23]$. Our study has confirmed that lack of sanitation and clean water remain highly prominent and attributable causes of infant mortality at a global-regional level, as well as at a country level as illustrated in previous studies [31]. Central-South America emerged as focal hotspot for lack of sanitation as a primary determinant of infant mortality (Figure 4). Spatial concentrations of high decomposition values for lack of access to water or sanitation showed almost identical spatial distributions (i.e., a duel hygiene problem) and were observed in SSA, South America, and Central Asia. Furthermore, given the increase in relative importance of the lack of access to water and sanitation over the study period (Figure 6), this suggests that there is still much room for improvement in the provision of hygienic environments for infants and young children in many countries.

The protective association between increasing maternal education (proxied by female education years in our study) and infant mortality has been described in previous literature [32]. This is likely a result of better birth spacing (i.e., longer birth intervals) [32], better awareness and utilization of prenatal care and health services [33], and higher income, which improves infants' health through the ability to purchase goods and services [34].

Interestingly, out-of-pocket health expenditure emerged as a significant and highly attributable determinant of infant mortality in Europe. A recent study assessing health system determinants of infant mortality also found out-of-pocket health expenditure to be a significant determinant following multivariable adjustment [12]. This is attributed to a weak health 
financing system that cannot function without the additional cushion of out-of-pocket costs. This has both a direct and indirect impact on increasing the risk of adverse infant and child outcomes. The direct effect of these medical costs is evident and households often then borrow or sell assets. The loss of income from sick family members constitutes the indirect effect [35].

The assessment of temporal changes in IMR and the attributability of its associated determinants is important as neither is static, and time-appropriate policy decision-making is critical. Our study suggests that improvements have been made with regards to infant mortality attributed to health service provision (DPT immunisation coverage and out-of-pocket health expenditure) and young mothers (adolescent fertility), as suggested by a decreasing importance of these determinants. However, significant levels of IMR attributable to these factors still remain. Lapses in efforts to reduce infant mortality and associated contributing factors can lead to a slowing of and even a reversal of the decline in mortality rates in coming years.

\section{Underestimation of IMR}

Our model suggests that significant underestimation (underreporting) of IMR occurred in some countries, particularly in SSA. Reliable infant and child mortality data are critical for planning health interventions and assessing progress, yet such data are often not available or reliable in developing countries [36], especially in SSA [37]. This study also makes a contribution by more accurately estimating IMR in the presence of underreporting in areas with known higher IMR risk that have poor data sources. This has a definite application to other MDG health outcome indicators when estimating "true" progress.

\section{Limitations}

Much of the WDI data comes from individual member countries and is compiled by internationally recognized organizations [13]. However, the quality of global data still depends on how well the individual national systems perform. We therefore cannot discount that differential data quality by country may have affected our findings. The World Bank has worked to help developing countries improve national statistical systems and hence the quality of their data. Therefore, changes in data quality with time may also affect the observed temporal trends. Substantial missing data for certain key indicators (e.g., maternal survival, female education) not included in our model is also a limitation, and the confounding influence of these potential high impact determinants was not adjusted for. Lastly, given the use of an ecological study design, caution should be taken when making direct causal inferences (the so called "ecological fallacy"). AFp can be incorrectly overestimated if confounding is not taken into account (i.e., risk coefficients can be overestimated) [11]. This can occur for the formula used in this study if unadjusted risk coefficients are utilized. We have tried to limit this potential bias by use of multivariable adjusted risk coefficients. A recent study based on data from 137 countries suggested that suboptimal breastfeeding may rank higher as a risk factor for child mortality than poor water and sanitation [38]. Thus we cannot also discount the potential impact (or contribution) of such a missing indicator in our analyses. Future applications of our proposed framework should include this and other potentially key missing indicators.

\section{Conclusions}

This study contributes to our understanding of the global burden of infant mortality and disaggregation to the country level with regards to associated highimpact determinants for policy tailoring. Maternal mortality (survival) appeared to be the most prominent risk factor for infant mortality, followed by lack of access to sanitation, female education, and lack of access to water. Substantial heterogeneity exists across regions and countries with regards to the most important factor. The model also suggests that there is potentially significant underestimation of IMR in regions known for poorer data quality. The framework will potentially aid policymakers in retailoring time-appropriate interventions to more effectively reduce IMR and associated high-risk indicators in the post-Millennium Development Goal era and thus potentially build on momentum garnered for associated determinants during this era.

\section{Appendix 1: Spatial clustering of high decomposition values for selected determinants at a country level, 1990-2011}

In general significant clustering of high attributability (decomposition values) for all selected determinants was observed (Figure 7a-d below), especially in SSA in general.

HIV: significant concentration of high decomposition values for HIV was concentrated in SSA (Figure 7a).

Lack of Sanitation: African countries again showed the highest attributably of IMR due to lack of sanitation (Figure 7b), as well as strong spatial clustering of high decomposition values due lack of sanitation. However, high and significant spatial clustering attributably due to sanitation was also in South America and parts of Central Asia. 


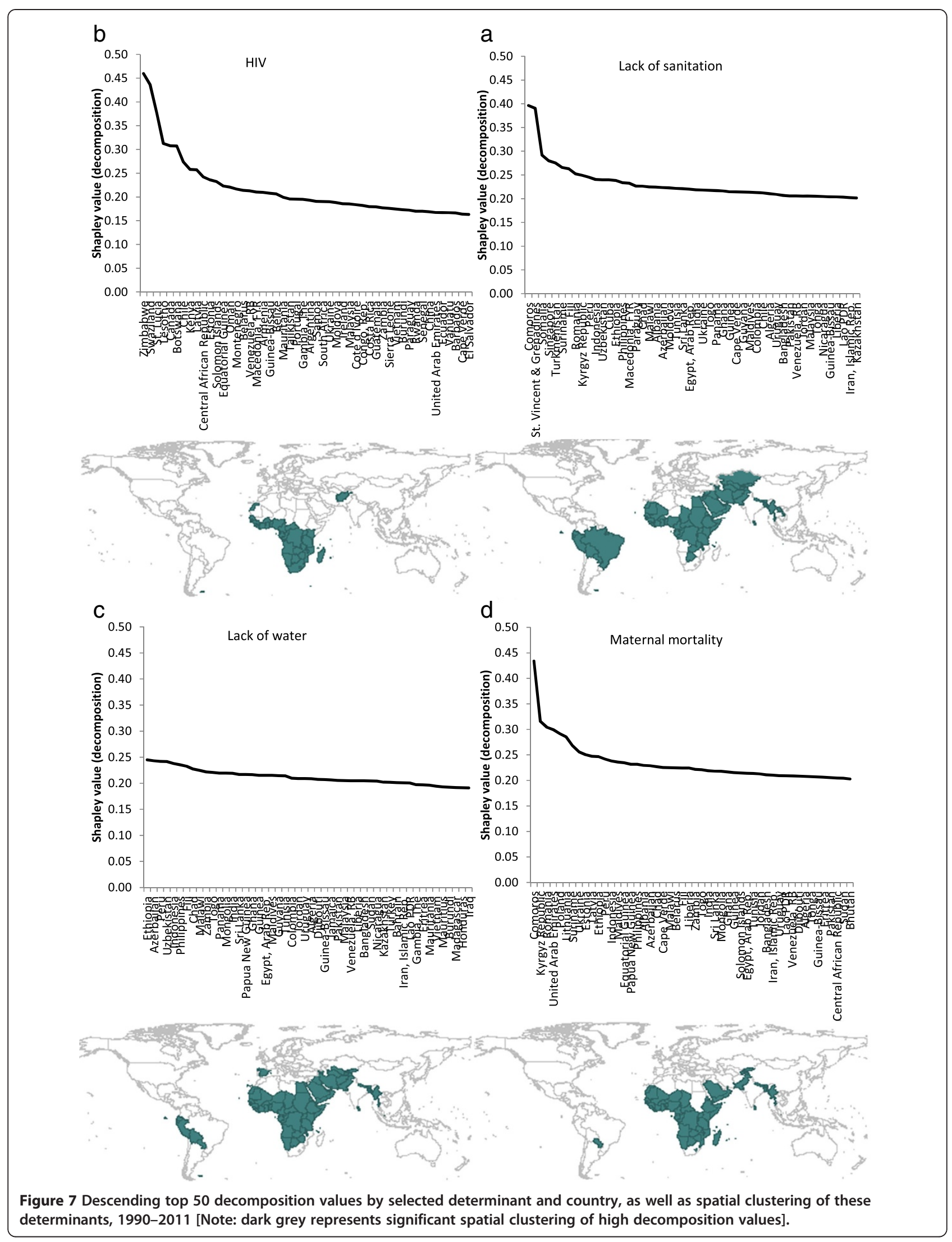


Lack of Water: The distribution of significant clustering of high decomposition (importance) of lack of access to water was almost identical to that of lack of access to sanitation, particularly in SSA, central Asia, and parts of South America (Figure 7c).

Maternal Mortality: Significant spatial concentration of high contiguous decomposition values for maternal mortality as a determinant of infant mortality was largely concentrated in SSA (Figure 7d) with sporadic clustering in parts of the Middle East and Central Asia.

\section{Abbreviations}

AFp: Attributable fraction (population); IMR: Infant mortality rate DPT: Diphtheria-Pertussis-Tetanus; GDP: Gross domestic product; HIC: High-income countries; HIV: Human immunodeficiency virus; LIC: Low-income countries; MDG: Millennium Development Goal; MIC: Middle-income countries; SSA: Sub-Saharan Africa; VIF: Variance inflation factors; WDI: World Development Indicators; WHO: World Health Organization.

\section{Competing interests}

The authors declare that they have no competing interests.

\section{Authors' contributions}

$\mathrm{BS}$ and KS contributed to the conception and design, interpretation of data, and drafting of the manuscript. BS contributed to the acquisition of data and analysis. BS and KS have given final approval of the version to be published and agree to be accountable for all aspects of the work in ensuring that questions related to the accuracy or integrity of any part of the work are appropriately investigated and resolved. Both authors read and approved the final manuscript.

\section{Acknowledgments}

We acknowledge the World Bank for compiling and making freely available the WDI database, without which this study would not have been possible.

\section{Author details}

${ }^{1}$ Discipline of Public Health Medicine, School of Nursing and Public Health, George Campbell Building, Howard College Campus, University of KwaZulu-Natal, Durban 4001, South Africa. ${ }^{2}$ Faculty of Commerce, Law and Management, University of the Witwatersrand, Johannesburg, South Africa.

\section{Received: 10 February 2014 Accepted: 7 October 2014}

\section{Published online: 19 October 2014}

\section{References}

1. Reidpath D, Allotey P: Infant mortality rate as an indicator of population health. J Epidemiol Community Health 2003, 57:344-346.

2. Schell CO, Reilly M, Rosling H, Peterson S, Ekström AM: Socioeconomic determinants of infant mortality: a worldwide study of 152 low-, middle-, and high-income countries. Scand J Public Health 2007, 35:288-297.

3. Van Lerberghe W, Manuel A, Matthews Z, Cathy W: Make every mother and child count. Geneva: World Health Organization; 2005.

4. World Health Organization: World health statistics. Geneva: World Health Organization; 2012.

5. Mosley WH, Chen LC: An analytical framework for the study of child survival in developing countries. Popul Dev Rev 1984, 10:25-45.

6. Ezzati M, Lopez AD, Rodgers A, Vander Hoorn S, Murray CJ: Selected major risk factors and global and regional burden of disease. Lancet 2002, 360:1347-1360.

7. Sartorius K, Sartorius BK: A spatial model to quantify the mortality impact of service delivery in Sub-Saharan Africa: an ecological design utilizing data from South Africa. Int J Health Geogr 2013, 12:8.

8. Northridge ME: Public health methods-attributable risk as a link between causality and public health action. Am J Public Health 1995, 85:1202-1204.
9. Lopez AD, Mathers CD, Ezzati M, Jamison DT, Murray CJ: Global and regional burden of disease and risk factors, 2001: systematic analysis of population health data. Lancet 2006, 367:1747-1757.

10. Shorrocks AF: Decomposition procedures for distributional analysis: a unified framework based on the Shapley value. J Econ Inequal 2013, 11:99-126.

11. Rockhill B, Newman B, Weinberg C: Use and misuse of population attributable fractions. Am J Public Health 1998, 88:15-19.

12. Muldoon KA, Galway LP, Nakajima M, Kanters S, Hogg RS, Bendavid E, Mills EJ: Health system determinants of infant, child and maternal mortality: A cross-sectional study of UN member countries. Global Health 2011, 7:42.

13. Group WBDD: World Development Indicators 2012. 2012. World Bank-free PDF

14. Gakidou EE, Murray CJL, Frenk J: Defining and measuring health inequality: an approach based on the distribution of health expectancy. Bull World Health Organ 2000, 78:42-54.

15. Hogan MC, Foreman KJ, Naghavi M, Ahn SY, Wang M, Makela SM, Lopez AD, Lozano R, Murray CJ: Maternal mortality for 181 countries, 1980-2008: a systematic analysis of progress towards Millennium Development Goal 5. Lancet 2010, 375:1609-1623.

16. Royall RM: Model robust confidence intervals using maximum likelihood estimators. Int Stat Rev 1986, 54:221-226.

17. O'brien RM: A caution regarding rules of thumb for variance inflation factors. Qual Quant 2007, 41:673-690.

18. Assuncao RM, Reis EA: A new proposal to adjust Moran's I for population density. Stat Med 1999, 18:2147-2162.

19. Anselin L, Syabri I, Kho Y: GeoDa: an introduction to spatial data analysis. Geogr Anal 2006, 38:5-22.

20. Getis A, Ord J: The analysis of spatial association using distance statistics. Geogr Anal 1992, 24:189-2006.

21. Getis A, Ord J: Local spatial autocorrelation statistics: distributional issues and an application. Geogr Anal 1995, 27:287-306.

22. StataCorp: Stata Statistical Software: Release 12. College Station, TX: StataCorp LP; 2011.

23. Black RE, Morris SS, Bryce J: Where and why are 10 million children dying every year? Lancet 2003, 361:2226-2234.

24. Sartorius B, Sartorius K: Identifying and targeting mortality disparities: a framework for Sub-Saharan Africa using adult mortality data from South Africa. PLoS One 2013, 8:e71437.

25. Walker N, Tam Y, Friberg IK: Overview of the Lives Saved Tool (LiST). BMC Public Health 2013, 13:1-6.

26. Houweling TA, Kunst AE: Socio-economic inequalities in childhood mortality in low-and middle-income countries: a review of the international evidence. Br Med Bull 2010, 93:7-26.

27. Scott KG, Mason CA, Chapman DA: The use of epidemiological methodology as a means of influencing public policy. Child Dev 1999, 70:1263-1272

28. Sartorius BK, Kahn K, Vounatsou P, Collinson MA, Tollman SM: Young and vulnerable: Spatial-temporal trends and risk factors for infant mortality in rural South Africa (Agincourt), 1992-2007. BMC Public Health 2010, 10:645.

29. Sartorius B, Sartorius K, Chirwa TF, Fonn S: Infant mortality in South Africadistribution, associations and policy implications, 2007: an ecological spatial analysis. Int J Health Geogr 2011, 10:61

30. Anderson FW, Morton SU, Naik S, Gebrian B: Maternal mortality and the consequences on infant and child survival in rural Haiti. Matern Child Health $J$ 2007, 11:395-401.

31. Rutstein SO: Factors associated with trends in infant and child mortality in developing countries during the 1990s. Bull World Health Organ 2000, 78:1256-1270.

32. Cleland JG, Van Ginneken JK: Maternal education and child survival in developing countries: the search for pathways of influence. Soc Sci Med 1988, 27:1357-1368.

33. Jain AK: Determinants of regional variations in infant mortality in rural India. Popul Stud 1985, 39:407-424.

34. Schultz TP: Interpretation of relations among mortality economics of the household and the health environment; 1979.

35. Leive A, Xu K: Coping with out-of-pocket health payments: empirical evidence from 15 African countries. Bull World Health Organ 2008 86:849-856C. 
36. Guillot M, Gerland P, Pelletier F, Saabneh A: Child mortality estimation: a global overview of infant and child mortality age patterns in light of new empirical data. PLoS Med 2012, 9:e1001299.

37. Mathers CD, Ma Fat D, Inoue M, Rao C, Lopez AD: Counting the dead and what they died from: an assessment of the global status of cause of death data. Bull World Health Organ 2005, 83:171-177c

38. Roberts T, Carnahan E, Gakidou E: Burden attributable to suboptimal breastfeeding: a cross-country analysis of country-specific trends and their relation to child health inequalities. Lancet 2013, 381:S126.

doi:10.1186/s12963-014-0029-6

Cite this article as: Sartorius and Sartorius: Global infant mortality trends and attributable determinants - an ecological study using data from 192 countries for the period 1990-2011. Population Health Metrics 2014 12:29.

\section{Submit your next manuscript to BioMed Central and take full advantage of:}

- Convenient online submission

- Thorough peer review

- No space constraints or color figure charges

- Immediate publication on acceptance

- Inclusion in PubMed, CAS, Scopus and Google Scholar

- Research which is freely available for redistribution 